Citation for this paper:

Ortega, E.; Flores, R. “Aeroelastic analysis of parachute deceleration systems with empirical aerodynamics" Proceedings of the institution of mechanical engineers - Part G. Journal of aerospace engineering. (2019). ISSN 0954-4100.

\title{
AEROELASTIC ANALYSIS OF PARACHUTE DECELERATION SYSTEMS WITH EMPIRICAL AERODYNAMICS
}

\author{
Enrique Ortega ${ }^{1}$ and Roberto Flores ${ }^{2,3}$ \\ ${ }^{1}$ Serra Hunter professor at Escola Superior d'Enginyeries Industrial, Aeroespacial y Audiovisual de Terrassa, \\ Universitat Politècnica de Catalunya. Colom 1-11, 08222 Terrassa, Spain. \\ ${ }^{2}$ Escola Superior d'Enginyeries Industrial, Aeroespacial y Audiovisual de Terrassa, Universitat Politècnica de \\ Catalunya. Colom 1-11, 08222 Terrassa, Spain \\ ${ }^{3}$ CIMNE - Centre Internacional de Mètodes Numèrics en Enginyeria. Gran Capità s/n, 08034 Barcelona, Spain.
}

\begin{abstract}
A technique for the aeroelastic solution of parachute decelerators is presented in this work. The methodology uses empirical aerodynamics, based on a filling-time inflation model and Ludtke's area law, coupled to two explicit structural solution approaches. A mass-springdamper technique allows solving the deployment of the system (when the grid is highly distorted) efficiently, and a finite element model is used for the accurate calculation of the structural loads and stresses during parachute opening and steady flight. The coupling strategy is staggered and the models share the same mesh. The methodology is intended for practical calculations of deceleration systems, and provides useful performance and structural data minimizing model complexity and computational cost. The suitability of the proposed technique is assessed by comparisons with reference test drop data.
\end{abstract}

\section{INTRODUCTION}

The design of improved deceleration systems and more efficient airdrop and aircraft emergency operations requires reliable and effective methods for the prediction of loads, stresses and trajectory of parachutes. For decades, designers and mission planners have relayed mainly on costly experimental approaches and simplified empirical-theoretical models, many of which have become classic literature and are still used for parachute analysis (e.g. Ewing and Knacke's reference design guides $[1,2])$. These methods are inexpensive, relatively simple to implement 
and have a long tradition in the parachute community thanks to their reliability, widely proven in practice. Examples of recent applications combining empirical legacy models for an effective simulation of precision airdrop operations can be found in [3-5]. Over the last years, as computers became more and more powerful and cost-effective, higher-fidelity prediction approaches based on numerical simulation have been developed. Among other features, current numerical methods allow for more extensive and detailed analyses, can provide information sometimes difficult to obtain from tests, and are also useful for calculating the specific input data required by the traditional codes employed in routine practices. Hence, increasing use of numerical simulation in the parachute design cycle could improve the system's performance and cut down development costs and time.

The operation of a typical (ballistic) parachute decelerator is generally analyzed into three different stages: deployment, inflation and terminal descent. The simulation of the terminal descent flight is the simplest. This can be studied using ballistic models with undeformable bodies (rigid or elastically connected) and steady aerodynamics [6, 7]. On the other hand, deployment and inflation pose major challenges. During these stages, the parachute rapidly undergoes radical changes in shape due to interaction with the extraction system and the
surrounding air. This implics detached turbulent flbws and large non-linear structural
displacements that must be solved simultaneously for an accurate solution. Also the contact interactions between different parts of the structure and a complex fabric behavior (e.g.

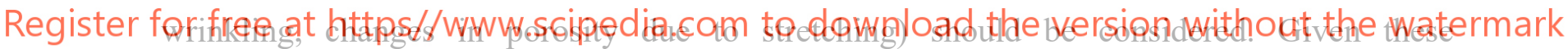

characteristics, the requirements for an accurate solution become overwhelming, but there are different levels of approximation available. The methodologies range from the mentioned simpler empirical methods to more detailed and costly numerical and fluid-structure interaction (FSI) modeling.

Regarding numerical approaches, the techniques developed up to the nineties are described in $[6,7]$ and a recent comprehensive review can be found in [8]. The methods involve different computational fluid dynamics (CFD) and structural dynamics (CSD) techniques with staggered or monolithic FSI coupling. The CSD models solve Newton's second law of motion for the structure subject to internal and external forces and constraints. The discretization is usually carried out by means of the finite element method (FE), using membrane and cable elements for the canopy fabric and suspension lines [9], or by means of simpler mass-spring-damper (MSD) models [10-13]. Shell elements can be also used for the fabric [14]. Regarding the CFD techniques employed, the first approaches were mainly based on potential flow panel methods 
[15-19]. These use surface grids for modeling the parachute canopy while boundary layers and wakes are discretized with unconnected free point vortices. Since only the fluid regions with concentrated vorticity are discretized, this approach is of the most effective for many practical (low-speed) parachute problems. Other solution approaches with full volume discretization allow for a detailed modeling of the surrounding fluid, but at the expense of a higher computational cost. Among the first grid-based approaches, arbitrary Lagrangian-Eulerian (ALE) Navier-Stokes solvers in conjunction with an MSD structural model [10], membrane elements [20] and shells [21] (including fabric porosity effects) can be found. An important family of high-fidelity methods also emerged in the context of the deforming-spatialdomain/stabilized space-time (DSD/SST) technique [22, 23], see applications in [24-26]. Other methods were developed in the context of the Immersed Boundary method [27] (with application to low Reynolds problems) and the Front Tracking method [11]. Models using Navier-Stokes equations coupled to rigid body trajectory models have been proposed in [28], and there are also successful commercial software applications [14, 29-31].

The methodology presented in this work is intended for fast aeroelastic simulation of ballistic

parachutes. The aim is to go further inscope and detail than low-fidelity methods, but withqut
the need to resort to expensive numerical techniques. To keep the computational requirements
low, the parachute aerodynamics is resolved by means of a well-known empirical model, and

two different explicit CSD methods are used to meet the requirements of each stage of flight

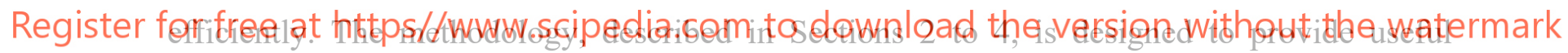

operation and structural data for practical analysis. Several validation test cases are provided in

Section 5 to illustrate the performance achieved. Finally, the main conclusions are outlined in Section 6.

\section{STRUCTURAL MODEL}

The deployment, inflation and terminal descent of the parachute are solved by means of two different approaches. Since the deployment and the very initial phase of canopy inflation can be considered inelastic [32], a simpler and robust MSD model is employed first. Then, once the system is fully stretched and the canopy partially inflated, the elastic response becomes relevant. At this moment, the solution switches to a more accurate FE technique based on a large-displacement small-strain formulation. The MSD and FE models share the same grid, but the former uses an edge-based data structure for calculations (Figure 1). The analysis geometry is discretized using 2-node line, 3-node triangle and 4-node tetrahedral elements. Line elements 
are used for the suspension lines and seams/reinforcement tapes, while the canopy fabric is modeled with planar triangle elements. Solid tetrahedra are used for the suspended payload. To reduce the computational cost, groups of solid elements are lumped into rigid bodies when the expected deformation is negligible.
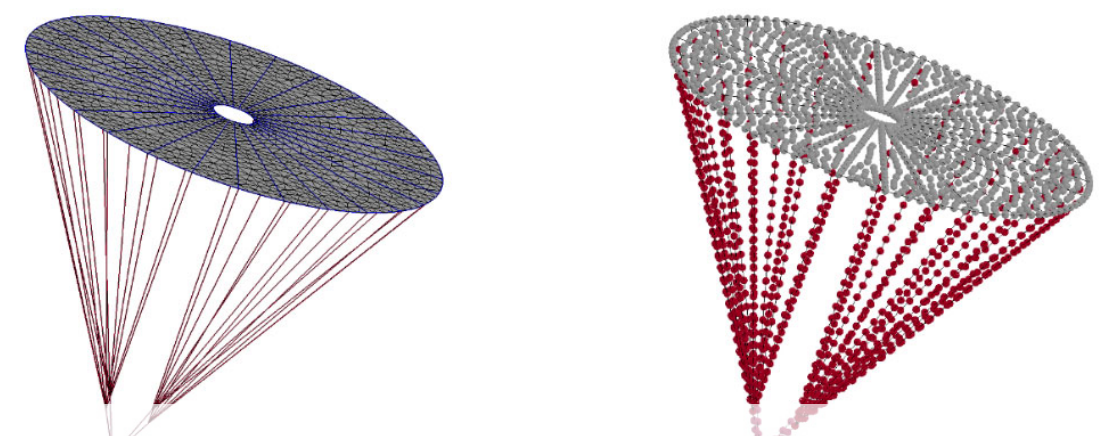

Figure 1. Discretization of a USAF C-9 parachute: Left: initial (undeformed) FE mesh; Right: MSD mesh.

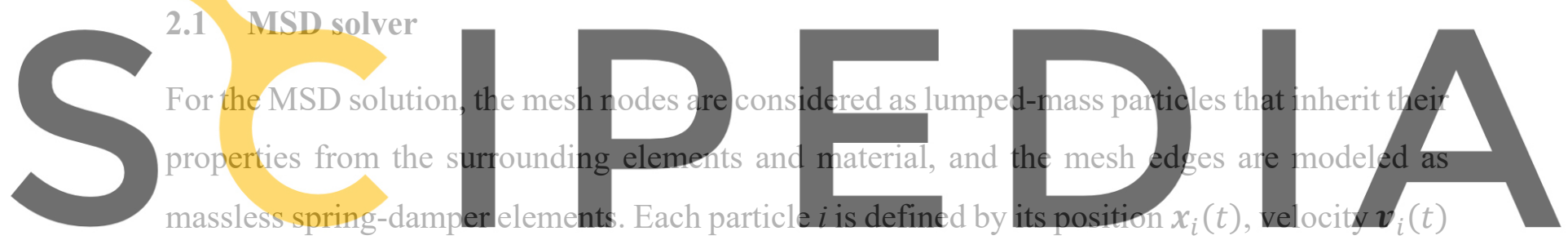

Register for free at https//WWW.scipedia.com to download the version without the watermark governs the dynamics, i.e.

$$
m_{i} \frac{d^{2} \boldsymbol{x}_{i}(t)}{d t^{2}}=\boldsymbol{f}_{i}(t) \quad i=1, n_{\text {particles }}
$$

where $\boldsymbol{f}_{\mathrm{i}}(t)$ is the sum of the internal and external forces acting on the $i^{\text {th }}$ particle. The external force has contributions from the parachute weight, the extraction system and the aerodynamics. The particle's weight is accounted for adding the gravity vector $\boldsymbol{g}$ to the acceleration term in Eq. (1), and the extraction forces are defined by the user according to a desired deployment sequence. Time-varying distributed or point loads can be prescribed on the model to this purpose. The aerodynamic forces considered are the drag acting on the suspension lines, canopy and suspended payload; their calculation will be described in Section 3.

The internal force at each edge $\boldsymbol{l}_{i j}=\boldsymbol{x}_{j}-\boldsymbol{x}_{i}$ of the MSD mesh considers spring and damping contributions. Assuming that $A_{i j}$ is the cross-section area of the edge and $l_{i j}$ and $l_{i j}^{0}$ the current and initial (undeformed) lengths, respectively, the spring force is 


$$
\boldsymbol{f}_{i j}^{\mathrm{s}}=\left(E \frac{l_{i j}-l_{i j}^{0}}{l_{i j}^{0}} A_{i j}\right) \hat{\mathbf{e}}_{i j}
$$

being $E$ the Young's modulus and $\hat{\mathbf{e}}_{i j}$ a unit vector in the direction of $\boldsymbol{l}_{\mathrm{ij}}$. The damping force includes high and low-frequency terms. The former depends on the material stiffness and dilatational wave speed $c_{1}=\sqrt{E / \rho}$, and it is also calculated at the edge level as [33, 34]

$$
\boldsymbol{f}_{i j}^{\mathrm{dk}}=\left[\left(\frac{\beta E}{l_{i j}^{0}}+b_{1} \rho c_{1}\right) A_{i j}\left(\boldsymbol{v}_{j}-\boldsymbol{v}_{i}\right) \cdot \hat{\mathbf{e}}_{i j}\right] \hat{\mathbf{e}}_{i j}
$$

where $\boldsymbol{v}_{i}$ and $\boldsymbol{v}_{j}$ are the nodal velocities, $\rho$ the material's density, $\beta$ the stiffness-proportional Rayleigh damping factor (user input) and $b_{1} \approx 0.06$ [33]. The low-frequency mas damping term is calculated at each node by

$$
\boldsymbol{f}_{i}^{\mathrm{dm}}=-\frac{1}{2} \alpha \rho A_{i j} l_{i j} \boldsymbol{v}_{i} \quad ; \quad \boldsymbol{f}_{j}^{\mathrm{dm}}=-\frac{1}{2} \alpha \rho A_{i j} l_{i j} v_{j}
$$

and $\alpha$ is the Rayleigh damping parameter (user input). The nodal velocities in Eq. (4) are taken

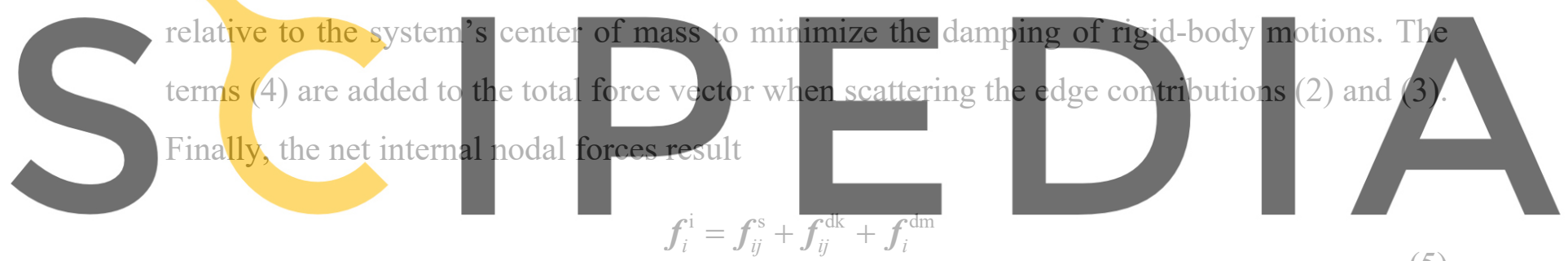

Register for free at https//www.scipediafcom to downflotad the version without the watermark

The model properties $E, A$ and $\rho$ are defined according to the underlying materials. For cable elements, the edge properties are the elastic modulus, cross-sectional area and density of the line. For membrane elements, the actual density and stiffness of the fabric are used (some authors suggest a slight increase of $E$, e.g. [11]), and the cross-section is estimated using the corresponding surface area and thickness of the surrounding elements. Seams and fabric reinforcements are modeled with cable elements that take equivalent properties. It should be noted that the stiffness of the edges belonging to the fabric is augmented with increasing strains to keep the elongation realistic (usually below $5 \%$ in textile materials). Procedures to avoid a negative impact of the increased rigidity on the allowable time increment are discussed in [35], and guidelines for a proper adjustment of the damping factors $\alpha$ and $\beta$ are given in $[33,36]$.

The wrinkling of textile materials under compressive stress is accounted for by setting the force in Eq. (2) to zero whenever $l_{i j}<l_{i j}^{0}$. This applies strictly to edges belonging to suspension 
lines, but in the case of the fabric a small compressive stress (repulsion forces) is allowed to achieve a more realistic behavior, particularly during unfolding and deployment ( $E$ is lowered by a factor of $10^{-5}$ in this case). Nevertheless, the use of the simple MSD model proposed here should be limited to the early phase of canopy inflation. A more accurate model considering the complete strain-stress behavior of the fabric would be required for an extended range of application, see for example [13, 35, 37].

\subsection{FE solver}

The FE model employed in this work is described in detail in [33]. The formulation derives from the principle of virtual work. For a system in equilibrium subject to a virtual displacement field $\delta u_{i}$, the incremental works of the internal and external forces must be equal. In a dynamic problem, the external actions are augmented with the inertial forces $-\rho d^{2} u_{i} / d t^{2}$, thus

$$
\sum_{i} \int_{\Omega} \rho \frac{d^{2} u_{i}}{d t^{2}} \delta u_{i} d \Omega+\sum_{i, j} \int_{\Omega} \sigma_{i j} \delta \varepsilon_{i j} d \Omega=\sum_{i} \int_{\Gamma} t_{i} \delta u_{i} d \Gamma+\sum_{i} \int_{\Omega} b_{i} \delta u_{i} d \Omega
$$

Where $\sigma_{i j}$ denotes the components of the stress tensor, $\delta \epsilon_{i j}$ is the virtual strain field, $t_{i}$ is the

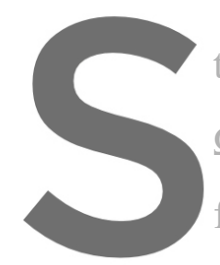

traction on the domain

$\Omega$. The discrete model is

functions; 2-node linear. 3-node triangular and 4 -

semi-discrete system includes damping terms, similarly as in the MSD model. This results in

Register for free at https//www.scipedia.egm to downloagd the version without the watermark

$$
M \frac{x_{i}}{d t^{2}}=b+t-I-C \frac{x_{i}}{d t}
$$

being $\boldsymbol{M}$ the mass matrix of the system (for increased efficiency the lumped form is used), $\boldsymbol{b}$ and $\boldsymbol{t}$ external nodal forces and $\boldsymbol{I}$ the internal force vector. The matrix $\boldsymbol{C}$ includes Rayleigh damping (which is a linear combination of the mass and stiffness matrices $\boldsymbol{C}_{\mathrm{Ray}}=\alpha \boldsymbol{M}+\beta \boldsymbol{K}$ ) and bulk viscosity to control high-frequency noise in the solution. Further details of the FE model can be found in $[33,34]$.

\subsection{Time integration}

In both MSD and FE solvers time integration is performed with the explicit midpoint rule, which is second-order time accurate. Given the position and velocity of a node at time $t^{n}$, the change in midpoint velocity is defined as

$$
\boldsymbol{v}_{i}^{n+1 / 2}-\boldsymbol{v}_{i}^{n-1 / 2}=\frac{\Delta t^{n+1}+\Delta t^{n}}{2} \cdot \frac{\boldsymbol{f}_{i}\left(t^{n}\right)}{m_{i}}
$$


where $f_{i}$ is the RHS of the acceleration equations (1) or (7) and $\Delta t^{\mathrm{n}}=t^{\mathrm{n}}-t^{\mathrm{n}-1}$. Once the intermediate velocities (i.e, at $t^{\mathrm{n}+1 / 2}=\left(t^{\mathrm{n}+1}+t^{\mathrm{n}}\right) / 2$ ) have been determined, the particle displacement is updated with

$$
\boldsymbol{x}_{i}^{n+1}=\boldsymbol{x}_{i}^{n}+\Delta t^{n+1} \cdot \boldsymbol{v}_{i}^{n+1 / 2}
$$

The velocity at the end of the step $\boldsymbol{v}^{\mathrm{n}+1}$ (used for example to compute the viscous forces) is extrapolated from the midpoint velocities. Since the midpoint rule is conditionally stable, the allowable time step $\Delta \mathrm{t}$ is limited by the minimum transit time of the dilatational waves across the mesh. For the undamped case and ignoring the effect of Poisson's ratio, $\Delta t \leq \min \left(l^{e} / c_{1}\right)$, where $l^{e}$ is the edge length and $c_{1}$ the material's dilatational wave speed. More details on the effects of damping and material properties are available in $[33,34]$. For the materials used in typical parachutes, the wave speed is on the order of $1 \mathrm{~km} / \mathrm{s}$, much higher that the speed of sound in air. This means that, at the time scales dictated by the stability limit of the structural solver, an explicit treatment of the aerodynamic forces is also acceptable.

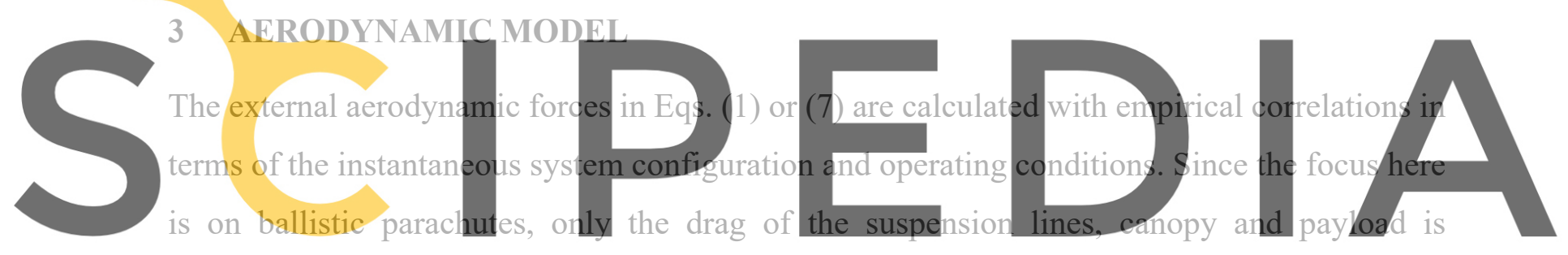

considered. The models employed are described below

Register for free at https//www.scipedia.com to download the version without the watermark

\subsection{Drag of lines and suspended payload}

For the aerodynamic drag acting on the suspension lines, each cable element $e$ is considered as a slender cylinder exposed to the wind. Hence, the element drag force is

$$
\boldsymbol{f}_{e}^{w}=1 / 2 \rho_{a} d_{e} l_{e} C_{d}\left\|\boldsymbol{V}_{e}^{t}\right\| \boldsymbol{V}_{e}^{t}
$$

where $\rho_{\mathrm{a}}$ is the air density (it depends on altitude) and $d_{e}$ and $l_{e}$ are the cable diameter and length, respectively. $C_{d}$ is the experimental cylinder drag coefficient (based on diameter) corresponding to the operation Reynolds number, and $\boldsymbol{V}_{e}^{t}=\left(\boldsymbol{V}_{w}-\boldsymbol{v}_{e}\right)^{\mathrm{t}}$ is the transverse component of the aerodynamic velocity (i.e. normal to the cable axis), which results from the wind speed $\boldsymbol{V}_{w}$ and the average kinematic velocity (i.e. ground speed) of the element $\boldsymbol{v}_{e}$.

The payload drag is calculated by correlations of experimental data defined by the user. For cargo containers, drag-area values in terms of body size and attitude can be found in [38]. Since there is large flow separation along the corners of typical parallelepiped cargo packages, the 
flow is turbulent in all phases of flight. This makes the payload drag coefficient not susceptible to variations with the operation Reynolds number (in the low Mach number regime).

\subsection{Canopy drag}

The canopy aerodynamic force is calculated in terms of an average pressure differential $\Delta \mathrm{P}_{\mathrm{a}}(\mathrm{t})$ responsible for drag and inflation [39]. This value is defined in terms of the instantaneous canopy drag $D(t)$ and projected area $S_{p}(t)$ as

$$
\Delta P_{a}(t)=\frac{D(t)}{S_{p}(t)}=q(t) \frac{\left(C_{D} S\right)_{t}}{S_{p}(t)}
$$

where $q(t)$ is the dynamic pressure and $\left(C_{D} S\right)_{t}$ the so-called parachute dynamic drag-area, a time-dependent parameter which increases from 0 to 100\% of its final value during inflation. Since its time signature is constant and repeatable for a given type of parachute [2], empiricalbased models can be used to determine $\left(C_{D} S\right)_{t}$ for a given parachute and flight condition. Then, the evolution of the canopy average pressure $\Delta P_{a}(t)$ can be obtained from Eq. (11), and the instantaneous force acting on each canopy element is calculated with
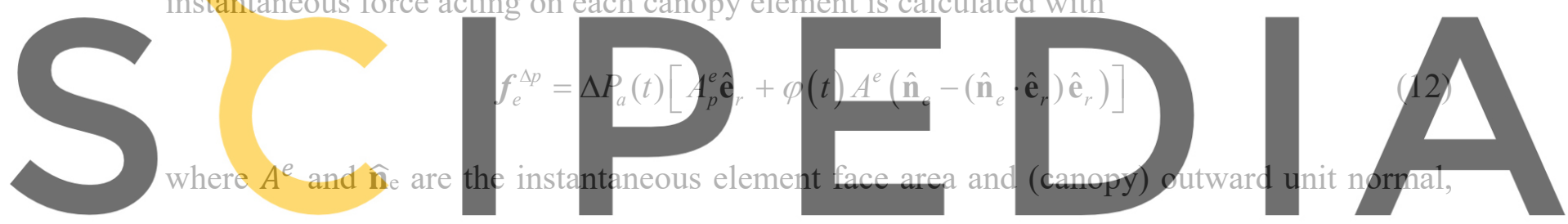

respectively; and $A_{p}^{e}$ is the face area projected in the direction of the instantaneous reference

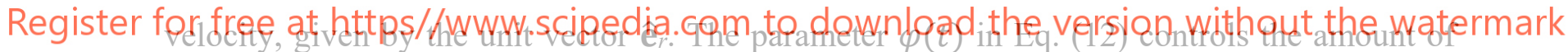

radial pressure and does not affect the total drag. In addition, as the radial pressure applied decreases from the canopy skirt to the apex, $\varphi(t)$ allows reproducing the typical increase in differential pressure caused by flow detachment at the skirt (see [2, 6]). Payload wake effects on the canopy drag can be accounted for in Eq. (11) by a reduction of the effective dynamic pressure [6]. The calculation of $\Delta P_{a}(t)$ and $\varphi(t)$ at each stage of flight is described below.

\subsubsection{Stage I: deployment}

During deployment, i.e. the interval between parachute release and lines snatch $\left(t_{s}\right)$, the canopy is considered as a piece of porous textile exposed to the wind. Hence, a constant drag coefficient $C_{D}$ is defined in Eq. (11) to obtain $\Delta P_{a}(t)$. The value can be obtained from flag or windsock experimental data [40]. In addition, the parameter $\varphi(t)$ is set to zero during deployment (the canopy generates only drag) and the reference aerodynamic velocity is calculated at each element as in Eq. (10), i.e. using the element kinematic velocity. Note that this value tends to 
the velocity of the canopy center of mass as snatch time is approached; thus, the barycenter velocity is used as reference for $t>t_{s}$.

\subsubsection{Stage II: opening and inflation}

The evolution of the canopy drag during opening and inflation is described in terms of the filling time $\left(t_{f}\right)$, i.e. the time necessary for the inflated canopy to attain its steady drag-area for the first time. For a given parachute and snatch conditions, the value of $t_{f}$ can be obtained from experimental data (if available) or empirical-based formulations. A simple estimate relying only on a single parachute parameter is derived from mass conservation arguments [41, 42]. The model states that in an incompressible flow, the parachute opens in a fixed distance $\Delta x$ regardless of its velocity [2]. Hence,

$$
\Delta x=t_{f} v_{s}=n D_{0} \rightarrow t_{f}=\frac{n D_{0}}{v_{s}}
$$

where $D_{0}$ is the canopy nominal diameter, $v_{S}$ the snatch velocity and $n$ a dimensionless fill constant. The latter depends on the canopy type and fabric porosity and is usually obtained from

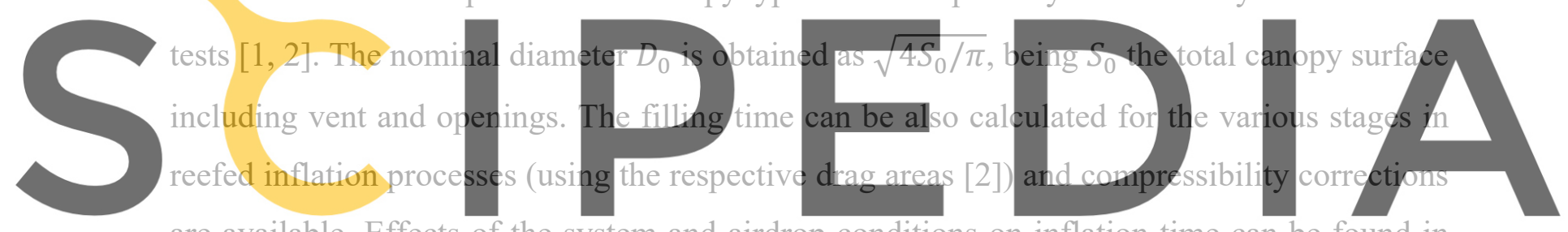

are available. Effects of the system and airdrop conditions on inflation time can be found in

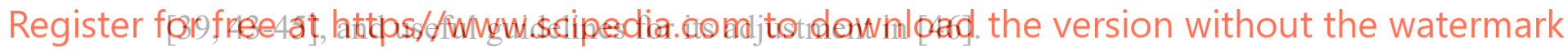

Using the filling time concept, the canopy inflation process is divided in two phases [47, 48].

During the initial phase, the canopy maintains a streamlined shape and the air enters without reaching stagnant conditions. The canopy $C_{D}$ is kept constant in Eq. (11) while the parameter $\varphi(t)$ in Eq. (12) starts to increase linearly with time in order to provide a radial inflation force, making the stretched canopy evolve into a near cylindrical form. The relative duration of the initial phase of inflation $\left(t_{i}\right)$ observed in testing is $t_{i} / t_{f} \leq 0.15[49,50]$, but the final value depends on the canopy shape. For simulation purposes, $t_{i}$ is calculated as the time the air needs to move from the skirt to the apex of the stretched canopy, i.e. $t_{i}=0.5 D_{0} / v_{s}$ (a more accurate estimate is given in [48]).

The final phase of inflation is characterized by a rapid increase of the parachute dynamic dragarea in Eq. (11). According to the Planz-Ludtke's law $[32,51]$, the drag-area signature of flatcircular parachutes can be approximated by 


$$
\left(C_{D} S\right)_{t}=\left(C_{D} S\right)_{0}\left[(1-\tilde{\eta})\left(\frac{t}{t_{f}-t_{i}}\right)^{3}+\tilde{\eta}\right]^{2}
$$

where $\left(C_{D} S\right)_{0}$ is the steady fully-open drag area. This value depends mainly on the canopy type and is independent of the Reynolds number (flow detachment at the canopy skirt makes the flow completely turbulent at all flight stages). If no specific data is available, parachute design guides provide suitable ranges for $\left(C_{D} S\right)_{0}$, e.g. [2]. Other effects on the canopy drag area due to Mach number, forebody wake, fabric porosity and lines length are also discussed in that reference. Finally, the parameter $\tilde{\eta}$ in Eq. (14) accounts for the aerodynamic area at the beginning of inflation $\left(C_{D} S\right)_{\mathrm{t}}$, and is calculated as in [48]

$$
\tilde{\eta}=\left(\frac{\left(C_{D} S\right)_{\mathrm{ti}}}{\left(C_{D} S\right)_{0}}\right)^{1 / 2}
$$

Regarding parameter $\varphi(t)$, it continues to increase (linearly) to the value prescribed by the user at $t=t_{f}$. For the circular-flat canopies studied here, a value $\varphi\left(t_{f}\right) \approx 0.5$ is chosen according

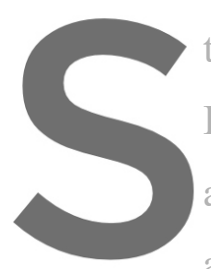
to the skirt-apex differential p Ludtke's law was determined from wind also applies to general deployment cases and and applications in $[2,54,55]$
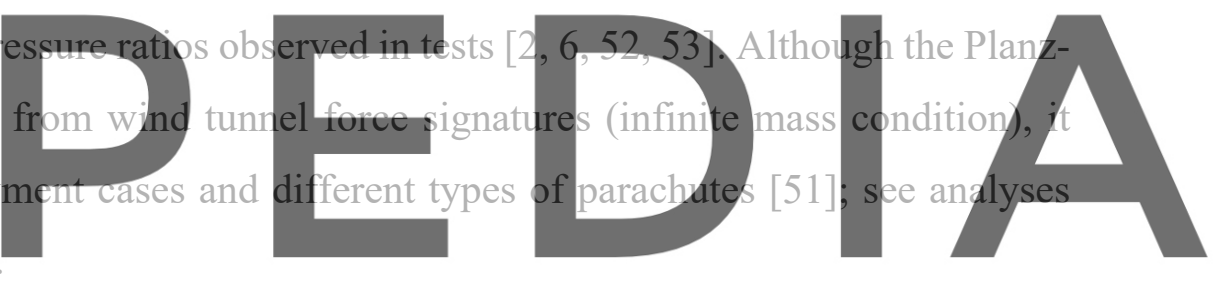

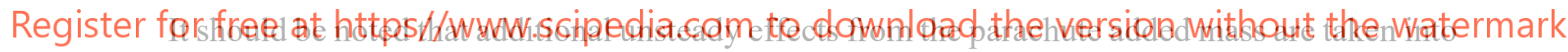

account when resolving the dynamics of the system during opening and inflation. The added mass model is described in Section 3.3.

\subsubsection{Stage III: terminal descent}

The terminal descent flight of the parachute starts at time $t_{t}=t_{s}+t_{f}$, when the canopy attains its steady drag area $\left(C_{D} S\right)_{0}$. Although this value is kept constant in Eq. (11) for $t>t_{t}$, some unsteadiness in the canopy drag can be still observed due to added mass effects and the parachute elasticity itself. This improves the simulation of the post-inflation stages (e.g. canopy over-inflation) and the deceleration process.

\subsection{Added mass}

The parachute added mass is the mass of air collected by the canopy (included mass, $M_{i}$ ) plus the surrounding air dragged with it (apparent mass, $\left.M^{\prime}\right)$. The added mass $\left(M_{a}=M_{i}+M^{\prime}\right)$ can generate important forces in unsteady motions, particularly for large parachutes and during the 
opening process. Models for determining $M_{a}$ are discussed in [6, 56-58]; here, the guidelines given in $[50,57]$ are followed. Accordingly, the included mass is defined by

$$
M_{i}=\rho_{a} \Omega_{c}(t)
$$

with $\rho_{a}$ denoting the air density (it depends on altitude) and $\Omega_{c}(t)$ the instantaneous canopy volume. For flat-circular canopies, the latter can be approximated as that of a hemisphere with radius $R_{c}(t)$, i.e. $\Omega_{c}=2 / 3 \pi R_{c}^{3}(t)$, but half-ellipsoids are also used. The canopy radius can be obtained from the actual canopy configuration or using approximations based on the inflation time. Both procedures have been tested. In the first case, the current canopy radius was calculated as the maximum perpendicular distance between a canopy node and the line connecting the centers of mass of the system and canopy (an estimate of the parachute axis). In the second case, a function for the instantaneous radius was fitted from the experimental data presented in [57]. Both procedures led to results which can be compared with experiments, but the first one required under-relaxation (e.g. $R_{c}\left(t_{n}\right)=R_{c}\left(t_{n-1}\right)+\xi\left(R_{c}^{\text {trial }}\left(t_{n}\right)-R_{c}\left(t_{n-1}\right)\right)$, with $0 \leq \xi \leq 1$ ) to avoid spurious accelerations of the system when updating the added mass (particularly at the start of inflation, when the canopy radius is not well-defined). In this sense, the second procedure was more stable and smooth. Therefore, it was decided to use the fitting function during the inflation stage, and the actual canopy size for $t>t_{f}$ (smaller variations are expected once the canopy area is fully developed). Note that this approach does not require additional user input data, because the instant drag area (Eq. (14)) can be used to estimate $\Omega_{c}(t)$ during inflation if no data is available. To this end, the $C_{D}$ based on projected area can be considered almost constant during the canopy opening, see [57, 59].

Regarding the apparent air mass entrained with the parachute, a widely used approximation is

$$
M^{\prime}=k^{\prime} \rho_{a} \pi R_{c}^{3}
$$

where $k^{\prime}$ is a constant depending on the parachute type and porosity. While the models available usually define $k^{\prime}$ for fully inflated canopies (see $[6,60]$ and [61] in terms of fabric porosity), some authors introduce a dependence on the actual shape of the inflating canopy. This can be achieved by relating $M^{\prime}$ with the included air mass and a ramping factor. For a solid flat-circular parachute $\left(k^{\prime}=0.25\right)$ this results in [50]

$$
M^{\prime}=3 / 8 M_{i} \varphi^{\prime}(t)
$$

where the factor $\varphi^{\prime}(t)$ ramps from zero to unity during the filling interval. 
The total added mass resulting from Eqs. (16) and (18) is taken into account when solving the dynamics of the system during canopy inflation and the terminal descent of the system. To this end, $M_{a}(t)$ is uniformly distributed along the canopy nodes and added to the material nodal masses for the calculation of the accelerations in the equation of motion.

\section{COUPLING AND SIMULATION SEQUENCE}

A staggered scheme is used to update the aerodynamic and structural fields. The aerodynamic loads are computed at the beginning of each structural time increment (given the simplicity of the fluid modelling, the impact on the computational cost is low). For a typical application this means some 10000 updates per second of physical time. This update frequency is higher than what is required for an explicit treatment of the aerodynamic field in a conformal grid. It enables use of explicit time integration, reducing the complexity of the algorithm compared to an implicit iterative coupling. In addition, updating the aerodynamics at each time increment introduces a natural damping mechanism on the high frequency response of the canopy, relaxing the need for artificial damping. Another advantage of this approach comes from the fact that the mesh is the same for the aerodynamic and structural solvers. Therefore, it does not require interpolation to transfer the results between the two fields.

The sequence of events occurring during the decelerated flight of the system is simulated as follows. For initialization, the canopy and lines of the initial model configuration (Figure 1) are packaged for release by collapse to the point that connects the risers and the payload (the edges of the MSD model are compressed to a very small length). Then, an initial velocity and orientation of the system is defined to start the deployment. The canopy and lines unfold freely subject to inertial, aerodynamic and extraction forces (if prescribed). The small repulsion forces allowed in the MSD model (see Section 2.1) make the unfolding process more realistic. The aerodynamic forces taken into account are the cables, canopy and payload drag described in Section 3. In this way, the system evolves until the lines and canopy are fully stretched; the snatch condition is automatically detected by monitoring the stress state of the mesh. At snatch time, $t=t_{s}$, the initial phase of inflation starts and the canopy is pressurized until $t=t_{s}+t_{i}$. Then, the drag area increases (Eq. (14)) to complete the filling interval at $t=t_{s}+t_{f}$. It is important to note that the structural solution switches from the MSD to the FE model when the canopy projected area reaches about $10-20 \%$ of its fully inflated value. Since the data structure and time integration scheme are the same for both solvers, the transfer is straightforward; only the calculation of the internal forces changes. Once the parachute is fully inflated, the drag area 
is kept constant for steady descent. The canopy shape can still experience slight variations mainly due to added mass and elastic effects.

The deployment sequence is illustrated in Figure 2 and Figure 3. The example involves an USAF C-9 parachute with payload mass $m_{l}=88 \mathrm{~kg}$, released at an altitude $h=2000 \mathrm{~m}$ with velocity $v_{r}=90 \mathrm{~m} / \mathrm{s}, \gamma \approx 45^{\circ}$ and $\theta=0^{\circ}(\gamma$ and $\theta$ denote the initial trajectory and pitch attitude angles, respectively). Figure 2 shows the initial MSD solution. The system deploys solely under the action of the mass and aerodynamic loads (no extraction force is prescribed). The snatch condition is attained about $1.1 \mathrm{~s}$ from release, and the solution switches to the FE solver at $1.2 \mathrm{~s}$.

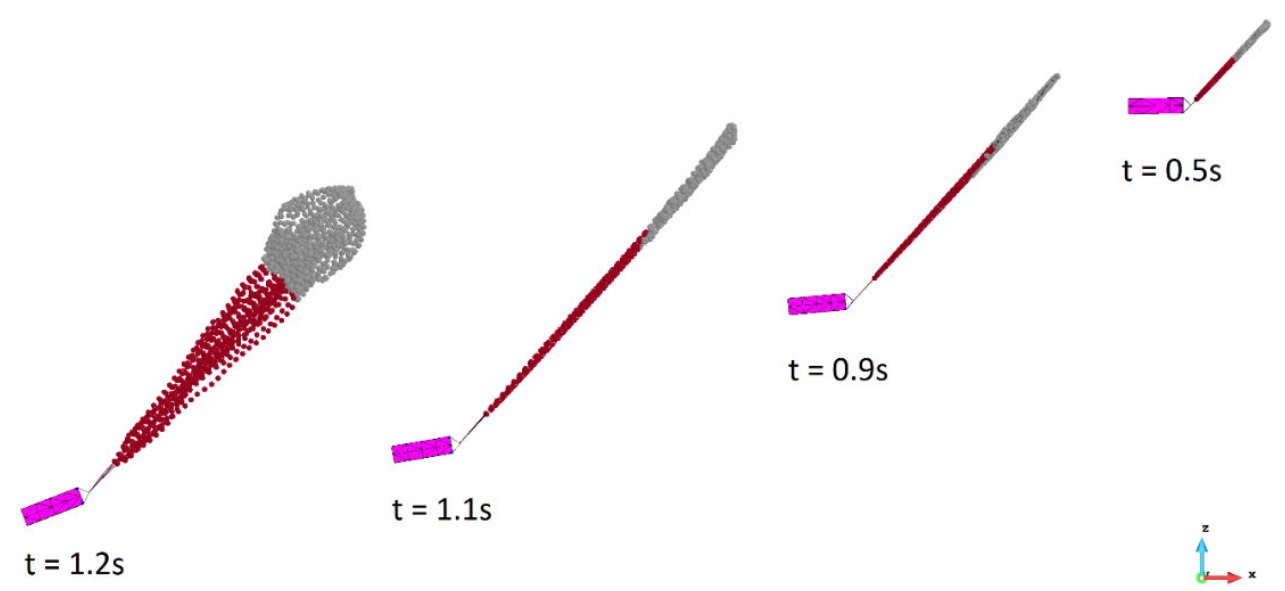

Figure 2. MSD solution of a C-9 parachute during deployment and initial opening stages (altitude $=2000 \mathrm{~m}, \mathrm{~m}_{\mathrm{p}}=$ $88 \mathrm{~kg}$ and $\mathrm{v}_{\text {release }} \approx 90 \mathrm{~m} / \mathrm{s}$ with $\gamma=45^{\circ}$ and $\theta=0^{\circ}$ ). Deployment and initial phase of inflation ends approximately at $1.1 \mathrm{~s}$ and $1.2 \mathrm{~s}$, respectively.

Parachute inflation continues with the FE model (Figure 3), and the opening process ends approximately at $2.2 \mathrm{~s}$ from release. The canopy area stabilizes after a short transient.
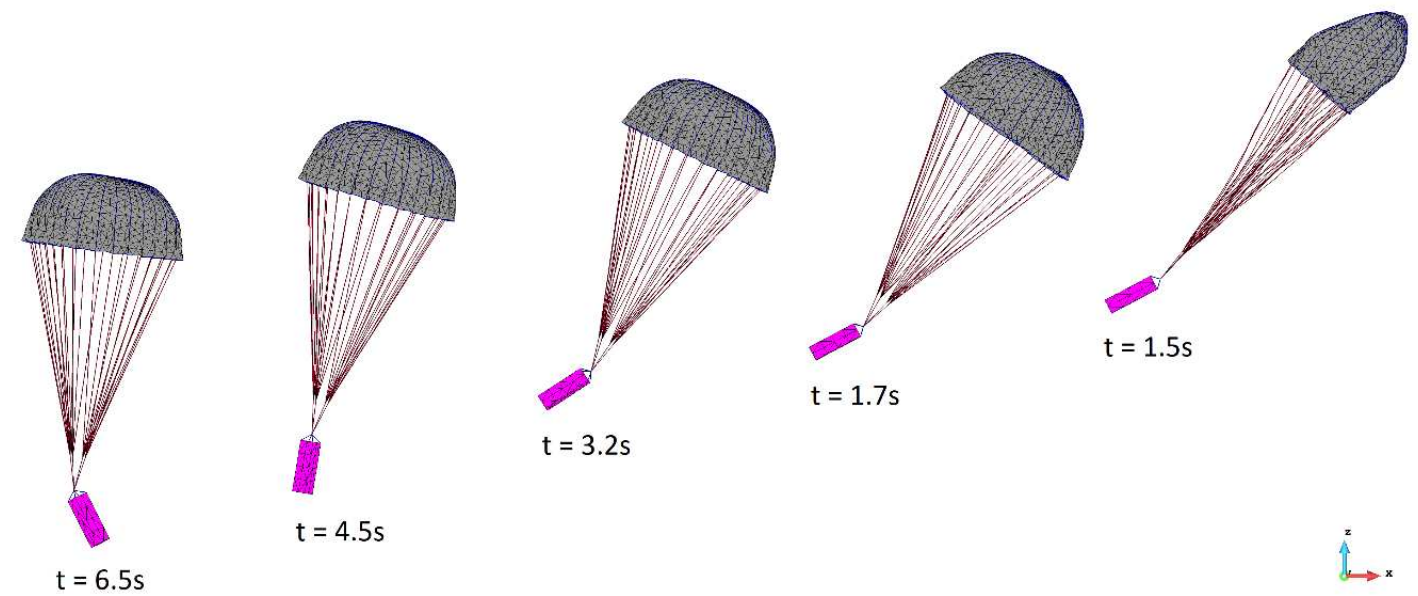

Figure 3. FE solution of a C-9 parachute during inflation and terminal descent (altitude $=2000 \mathrm{~m}, \mathrm{~m}_{\mathrm{p}}=88 \mathrm{~kg}$ and $\mathrm{V}_{\text {release }} \approx 90 \mathrm{~m} / \mathrm{s}$ with $\gamma=45^{\circ}$ and $\theta=0^{\circ}$ ). Inflation finishes approximately at $2.2 \mathrm{~s}$ from release. 


\section{VALIDATION EXAMPLES}

The test cases presented in this section are based on experimental results for standard full-scale USAF C-9 parachutes. The examples involve free-fall vertical tests [62] and controlled deployments at different velocities, altitudes and trajectory inclination angles [63].

\subsection{Computational model and problem setup}

The USAF C-9 is a low-porosity flat-circular parachute for personnel and cargo operations. The canopy has nominal diameter $D_{0}=8.53 \mathrm{~m}(28 \mathrm{ft})$ and is constructed with 28 gores and a small vent at the apex with diameter $0.1 D_{0}$. The suspension lines are $7.31 \mathrm{~m}(24 \mathrm{ft})$ long and are

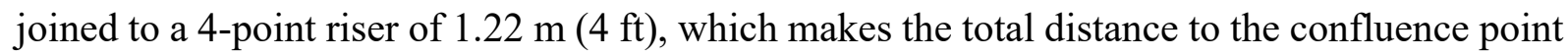
equal to $D_{0}$. The material properties used are those given in [62]. The canopy fabric (MIL-C7020 type I) has density $533 \mathrm{~kg} / \mathrm{m}^{3}$, Young's modulus 4.3E8 Pa and thickness $0.1 \mathrm{~mm}$. The density of the suspension lines (MIL-C-5040 type II) is $462 \mathrm{~kg} / \mathrm{m}^{3}$, the Young's modulus 9.7E10 $\mathrm{Pa}$ and the diameter $4 \mathrm{~mm}$. The material specifications for risers, skirt tape and vent webbing are MIL-W-4088, MIL-T-6134 and MIL-W-5625, respectively. The parachute canopy is discretized using 1932 triangle elements, 1461 cables are used for the suspension lines and reinforcement tapes and 96 tetrahedra simulate the suspended payload (see Figure 1). The material density of the payload is set in order to reproduce its mass but the real payload shape is not matched in this example. All the payload elements are lumped into a single rigid body.

For aerodynamic modeling, a steady drag coefficient based on nominal area $C_{D 0}=0.75$ is chosen [2], which gives a parachute steady drag area $\left(C_{D} S\right)_{0}=42.56 \mathrm{~m}^{2}$. The filling time for the free-fall vertical tests is obtained from [62] in terms of the test Froude number $\left(F_{r}=v_{s}^{2} / g D_{0}\right)$. For other deployment conditions, the filling time is set according to the parachute mass ratio $M_{r}=m_{l} / \rho_{a} D_{0}^{3}$ using the approximations given in [47]. These data are used to calculate the parachute filling constant $n$ (Eq. (13)), and this value is used for all the tests performed. Note that $n$ accounts for canopy shape, but also fabric porosity. Thus, the proposed adjustment of $t_{f}$ allows reproducing to a certain extent the actual characteristics of the parachutes used in the experiments. Additional test data for the C-9 parachute can be found in [2, 19, 50, 64].

\section{$5.2 \quad$ Test cases}

The first example involves free-fall vertical opening tests. In the experiments [62], the parachute is released from an $85 \mathrm{~m}(280 \mathrm{ft})$ crane using a static-line deployment technique. The parachute snatch velocity is adjusted by changing the length of the static lines and the payload is $152.4 \mathrm{~kg}(336 \mathrm{lbm})$, which gives a mass ratio $M_{r}=0.2$. For simulation, a static line is 
attached to the canopy apex while the other end is held fixed. At the beginning $(t=0)$, the parachute and the static lines are folded. Then, the system is released and allowed to fall due to gravity, unfolding the static line, suspension lines and canopy. When the snatch condition is detected (a threshold of $80 \%$ of the lines in tension is adopted), the fixed end of the static line is released and canopy inflation starts. To mimic a line-first extraction sequence, a small resisting force is added to the canopy edges during deployment when $l_{i j}<l_{i j}^{0}$ (see Eq. (2)). Some snapshots of the calculated results are shown in Figure 4.

(a)

(b)

(c)

(d)

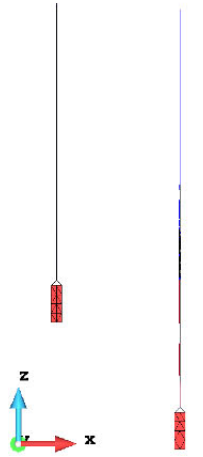

(e)

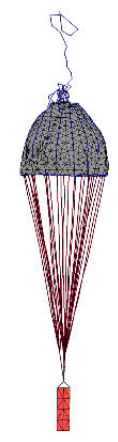

(f)

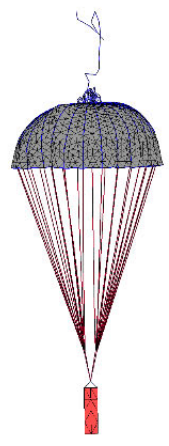

(g)

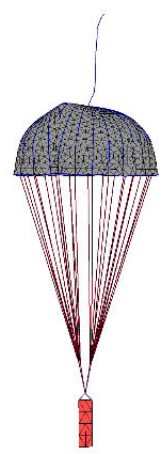

(h)

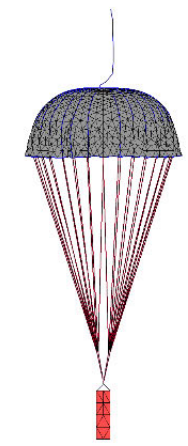

Figure 4. C-9 parachute free-fall vertical test with $M_{r}=0.2$ : (a) static line deployment, (b) static and suspension lines deployment, (c) system configuration immediately after lines snatch, (d-h) canopy inflation sequence.

The evolution of the canopy projected area ratio $\left(S_{p} / S_{0}\right)$ from the snatch condition is compared with experiments in Figure 5 [57, 63]. Despite some discrepancies in the behaviors of the reference models, the calculated area growth follows the expected behavior. The steady values reached in the simulation are $D_{p} / D_{0}=0.65$ and $h_{p} / D_{p}=0.45$. Values of 0.67 and 0.41 , respectively, are given in [1]; and a range of $0.67 \leq D_{p} / D_{0} \leq 0.7$ is reported in [2].

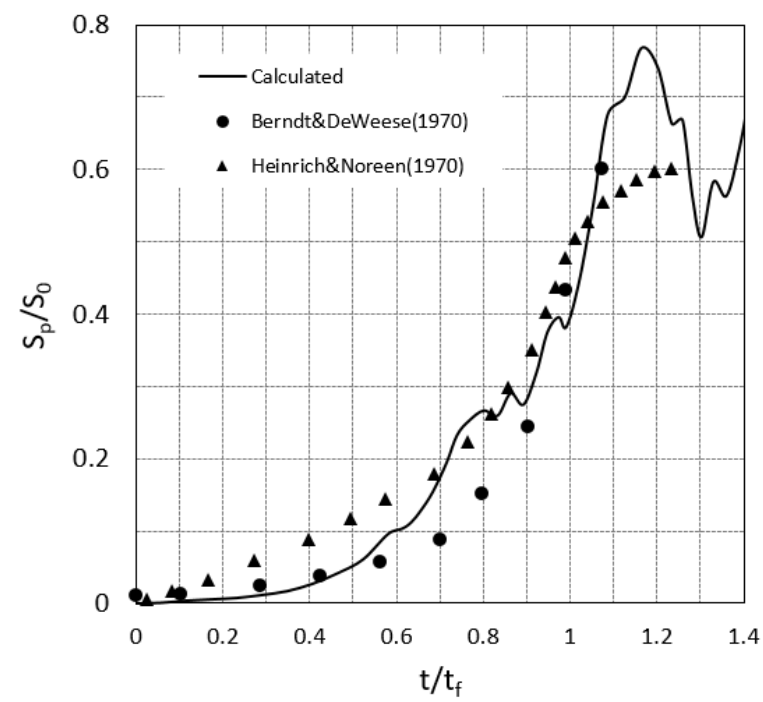

Figure 5. Evolution of the area ratio for a C-9 parachute in vertical free-fall $\left(\mathrm{M}_{\mathrm{r}}=0.2\right.$ and $\left.\mathrm{Fr}=5.3\right)$. 
The parachute opening force $\left(F_{o}\right)$ and center of mass velocity are compared with test data in Figure 6. The length of the static line is $12.2 \mathrm{~m}(40 \mathrm{ft})$ and the resulting snatch velocity is about $21 \mathrm{~m} / \mathrm{s}(70 \mathrm{ft} / \mathrm{s})$. Although the deceleration after the peak opening force is somewhat underestimated in the numerical solution (see Figure 7), the agreement with the test data is satisfactory. Note that the differences observed between the calculated and experimental results are in a band of \pm 10 percent, which is deemed acceptable for practical calculations (e.g. a tolerance of \pm 15 percent is assumed realistic in [51]). The computational cost of these simulations is about 2 minutes running on a conventional laptop computer.
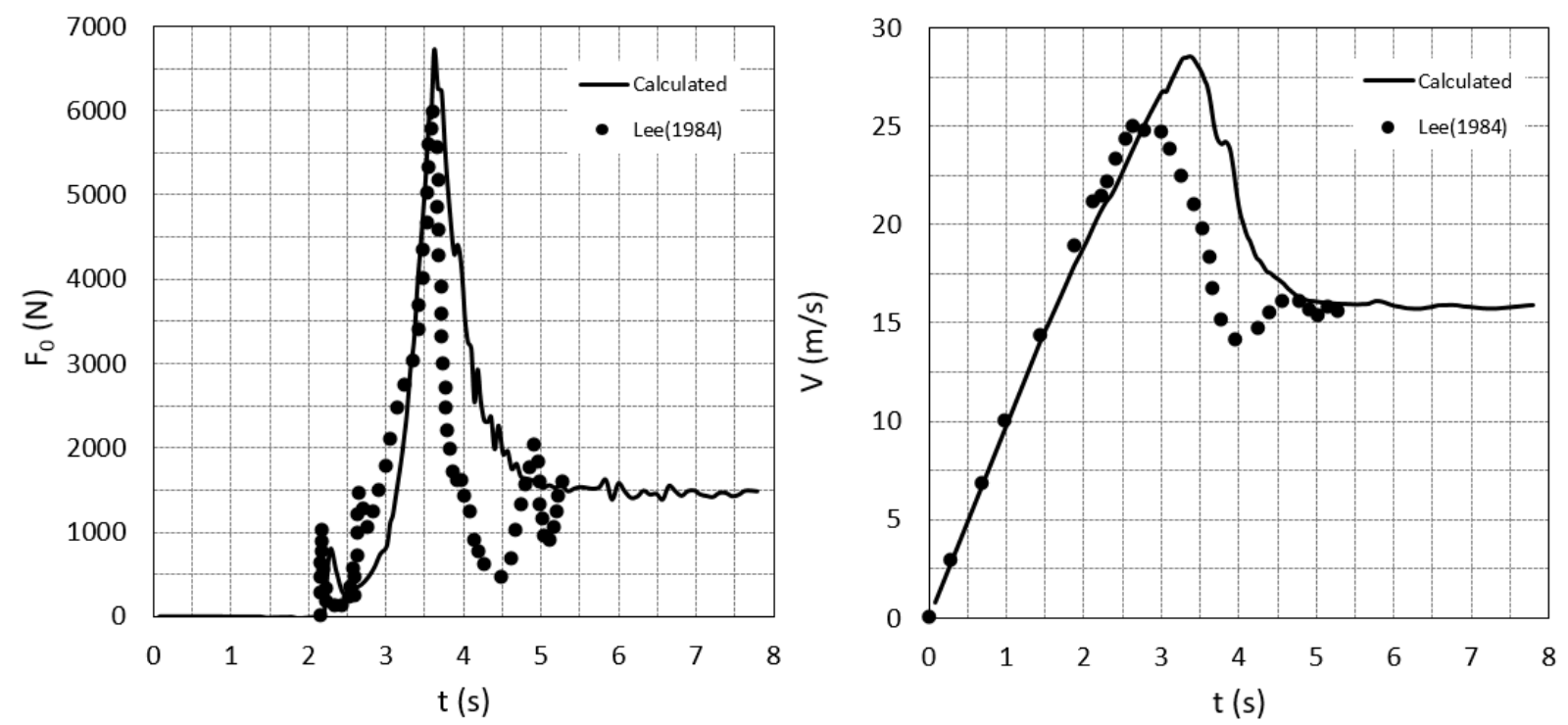

Figure 6. History of the opening force and velocity of a C-9 parachute (values measured from release). Vertical free-fall test with $\mathrm{M}_{\mathrm{r}}=0.2$ and $\mathrm{Fr}=5.3$.

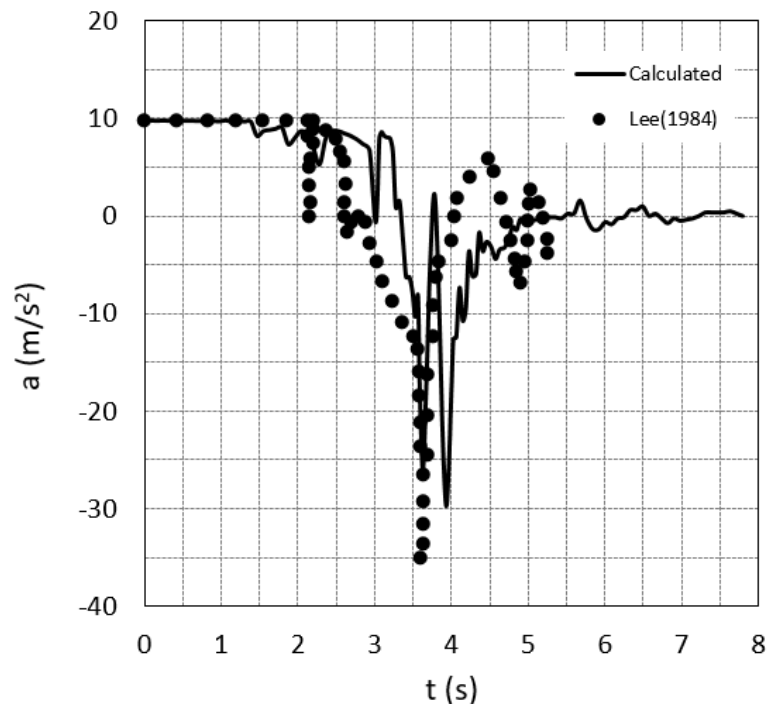

Figure 7. Acceleration history of a C-9 parachute. Vertical free-fall with $\mathrm{M}_{\mathrm{r}}=0.2$ and $\mathrm{Fr}=5.3$. 
The behavior of the peak force ratio $\left(X_{p}=F_{o} / m_{l} g\right)$ with the Froude number is studied next for a constant mass ratio $M_{r}=0.2$. In the reference data the upper limit of $F r$ in the low-range is 6 due to the available height of crane used for release in [62]. The high-range Fr number data correspond to vertical opening tests at altitudes between 1500-3600 m (5000-12000 ft) [63]. As observed in Figure 8, the increase of the opening force with the snatch velocity (smaller filling times) is well captured by the numerical solution.

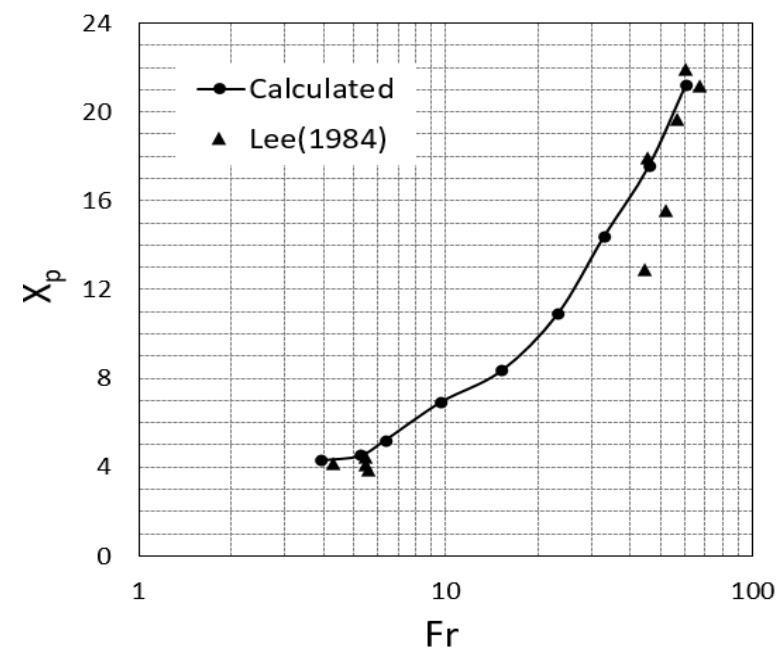

Figure 8. C-9 parachute opening peak force as a function of the Froude number (vertical free-fall tests at constant mass ratio $\mathrm{M}_{\mathrm{r}}=0.2$ ).

The effects of mass ratio, velocity and trajectory angle on the parachute opening force are investigated in the next example. The numerical results are compared with flight-test and semiempirical data presented in [63] and [65], respectively. In the simulations, the system is released at a constant sea-level altitude with different initial velocities and trajectory angles. The snatch conditions range is $50<v_{s}<80 \mathrm{~m} / \mathrm{s}$ and $10^{\circ}<\gamma<40^{\circ}$, and mass ratios $0.1<M_{r}<0.25$ are tested. Although the initial conditions have been adjusted to obtain a very close approximation to the test conditions, these cannot be exactly reproduced. Hence, the simulated and test mass ratios present slight differences. The results are displayed in Figure 9 in terms of the parachute opening shock parameter $\left(F_{0} / q_{s} S_{0}\right)$ and the operation Froude number $\left(v_{s}^{2} /\left(g D_{0} \sin \theta\right)\right)$. A satisfactory agreement with the experimental trends is achieved. 


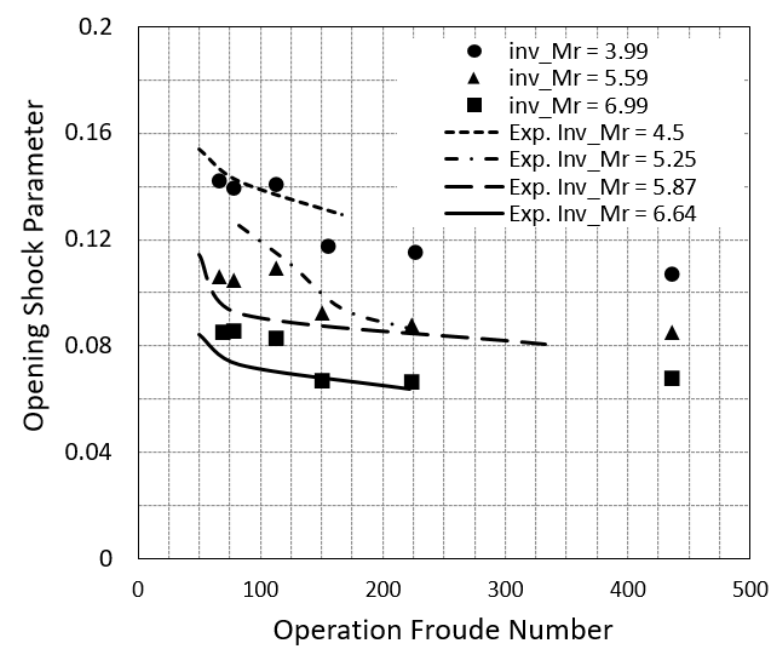

Figure 9. C-9 opening shock for different operation Froude numbers and inverse mass ratios (inv_Mr). Marker points indicate calculated data and lines represent the trend in the flight-test measurements (Berndt\&DeWeese1970).

Finally, the effect of deployment altitude is studied. The parachute payload is $m_{l}=199.6 \mathrm{~kg}$ and the snatch ranges $80<v_{s}<120 \mathrm{~m} / \mathrm{s}$ with $\gamma \approx 30^{\circ}$. The parachute mass ratio is $0.1<M_{r}<0.25$. Figure 10 shows the evolution of the opening force ratio $\left(X_{p}\right)$ with the snatch velocity for $h=1830 \mathrm{~m}$ and $3969 \mathrm{~m}$. The results show a very limited variation of $X_{p}$ with deployment altitude, especially at lower snatch velocities. The agreement with the experimental [63] and theoretical data [65] is satisfactory.
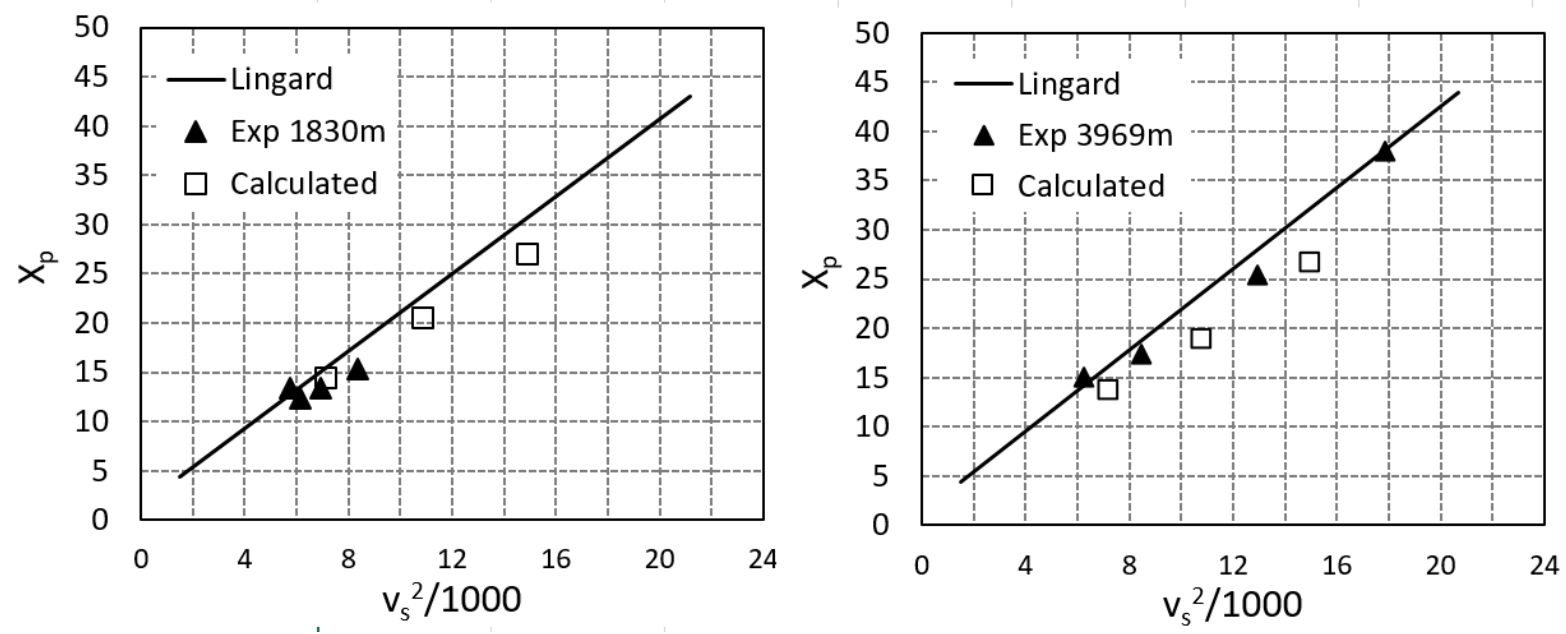

Figure 10. C-9 parachute opening force ratio as a function of the snatch velocity for deployment altitudes 1830 and $3969 \mathrm{~m}\left(\mathrm{~m}_{1}=199.6 \mathrm{~kg}\right)$.

When altitude increases and the change in air density becomes relevant, flight tests show that solid cloth parachutes open faster, causing larger opening forces for the same deployment conditions [39, 47, 63]. This behavior cannot be resolved in the present model. Since the opening distance $\Delta x=n D_{0}$ is fixed for a given type of parachute, the time required only 
depends on the snatch velocity. As seen in Figure 10, and particularly in Figure 11, this makes the difference between the calculated and experimental results larger with the altitude.

To take into account the effects of altitude on the opening time, an air density ratio $\left(\rho / \rho_{h=0}\right)^{k}$ can be included in Eq. (13) [1,2]. Correlations of the filling time in terms of parachute mass ratio can also be used. In this work, the density ratio is applied to the calculated filling time with a parameter $k=0.8$, estimated from the available experimental data. The correction greatly improves the numerical solution in the present test case (results denoted as tf corrected in Figure 11). Extensions to other parachutes and deployment conditions require further investigation. In this sense, corrections of the filling time in terms of the parachute mass ratio probably have a more solid experimental basis for its application.

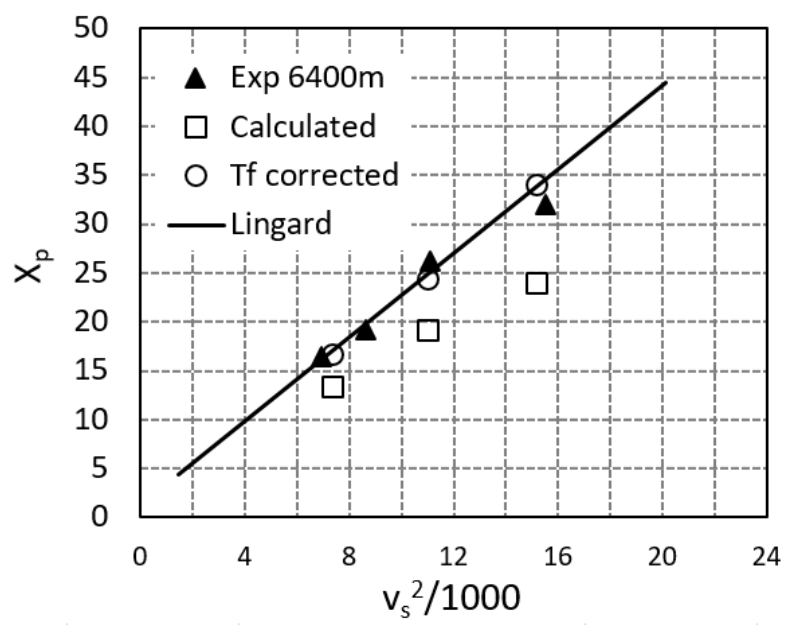

Figure 11. C-9 parachute opening force ratio as a function of the snatch velocity for deployment altitude $6400 \mathrm{~m}$ $\left(m_{1}=199.6 \mathrm{~kg}\right)$. Calculated results show the effects of correction of the filling time with local air density.

\section{CONCLUSIONS}

A methodology for the aeroelastic simulation of parachute decelerators has been presented. Its objective is to provide useful data for design and analysis without the need to resort to costly calculations. The method uses empirical aerodynamics, two explicit structural dynamic models and staggered coupling. The aerodynamic model is based on a filling-time inflation method and Ludtke's drag area law. This is reliable and inexpensive, can be applied to different types of parachutes and the input data required is easily obtained from the literature. Regarding the structural solution, a mass-spring-damper technique allows efficient solution of the deployment and early inflation phases while being insensitive to grid distortion effects. Afterwards, a finite element model takes over for a more accurate calculation of the structural loads and stresses during opening and steady descent flight. The methodology has been assessed using reference 
drop-test data for a USAF-C9 parachute. Although more extensive validation is still necessary, the results obtained so far are satisfactory and show the potential of the technique.

Although the proposed simulation approach is applicable to most parachute deceleration problems encountered in practice, limitations may arise when aerodynamic interference is a concern, e.g. when there is important interaction between the payload an the canopy, or in cluster configurations beyond the scope of the legacy models employed. In addition, there are aspects of the method that can be further developed. For example, contact and friction algorithms would greatly improve the treatment of parachute extraction and unfolding, and are also necessary to solve cluster configurations. Overall, compared to other methods, the proposed technique goes further in scope and detail than the low-fidelity approaches used in standard practice, and, most importantly, yields results comparable to higher-fidelity aeroelastic methods at a very small fraction of the cost.

\section{REFERENCES}

1. Ewing, E.G., Bixby, H. W., Knacke, T. W, Recovery systems design guide. Irving Industries Inc. Report AFFDL-TR-78-151, 1978.

2. Knacke, T.W., Parachute recovery systems design manual. Naval Weapons Center, Report AD-A247-666, 1991.

3. Mudrak, J., Development of a parachute deployment model for airdrop simulations. In Interservice/Industry Training, Simulation, and Education Conference (I/ITSEC), Paper No. 16133, 2016.

4. Moore, J., Morris, A., A hybrid parachute simulation environment for the Orion parachute development project. In 21st AIAA Aerodynamic Decelerator Systems Technology Conference and Seminar, 2011.

5. Potvin, J., Ray, E., Extrapolating the Trends of Test Drop Data with Opening Shock Factor Calculations: the Case of the Orion Main and Drogue Parachutes Inflating to 1st Reefed Stage. In 24th AIAA Aerodynamic Decelerator Systems Technology Conference, 2017.

6. Maydew, R.C., Peterson, C. W., Orlik-Rueckemann, K. J., Design and testing of highperformance parachutes (la conception et les essais des parachutes a hautes performances). Advisory Group for Aerospace Research and Development (AGARD), Report AGARD-AG-319, 1991.

7. Strickland, J.H., Higuchi, H., Parachute aerodynamics: an assessment of prediction capability. Journal of Aircraft, 1996. 33(2): p. 241-252.

8. Cao, Y., Nie, S., Wu, Z. , Numerical simulation of parachute inflation: a methodological review. Proceedings of the Institution of Mechanical Engineers, Part G: Journal of Aerospace Engineering, 2017. 0(0): p. 1-31.

9. Accorsi, M., Leonard, J., Benney, R., Stein, K. , Structural modeling of parachute dynamics. AIAA Journal, 2000. 38(1): p. 139-146.

10. Benney, R., Stein, K. R., Computational fluid-structure interaction model for parachute inflation. Journal of Aircraft, 1996. 33(4): p. 730-736.

11. Kim, J.D., Y. Li, and X. Li, Simulation of parachute FSI using the front tracking method. Journal of Fluids and Structures, 2013. 37: p. 100-119. 
12. Shi, Q., Reasor, D., Gao, Z., Li, X., Charles, R. D., On the verification and validation of a spring fabric for modeling parachute inflation. Journal of Fluids and Structures, 2015. 58: p. 20-39.

13. Cao, Y., Wu, Z., Song, Q., Sheridan, J., Numerical simulation of fluid-structure interaction in the opening process of conical parachute. The Aeronautical Journal, 2009. 113(1141): p. 191-200.

14. Tutt, B., Fluid Structure Interaction Parachute Benchmark Models in LS-DYNA®. In AIAA Aerodynamic Decelerator Systems (ADS) Conference, 2013.

15. Shirayama, S., Kuwahara, K., Computation of flow past a parachute by a threedimensional vortex method. In 24th Aerospace Sciences Meeting, 1986.

16. Sarpkaya, T., Methods of analysis for flow around parachute canopies. 11th Aerodynamic Decelerator Systems Technology Conference, Aerodynamic Decelerator Systems Technology Conferences, 1991.

17. Behr, V.L., Hailey, C. E., Peterson, C. W., Wolfe, W. P., An overview of the development of a vortex based inflation code for parachute simulation (VIPAR). Sandia National Laboratories Report SAND99-1259C, 1999.

18. Strickland, J.H., Homicz, G. F., Gossler, A. A., Porter, V. L., On the development of a gridless inflation code for parachute simulations. In 16th AIAA aerodynamic decelerator systems technology conference and seminar, Boston, MA, 2001.

19. Johari, H., Desabrais, K., A coupled fluid-structure parachute inflation model. In 17th AIAA Aerodynamic Decelerator Systems Technology Conference and Seminar. AIAA paper 2003-2146, 2003.

20. Ibos, C., Lacroix, C., Chuzet, L., Granville, D., Ibos, C., Lacroix, C., Granville, D. , SINPA, a full 3D fluid-structure software package for parachute simulation. In 14th Aerodynamic Decelerator Systems Technology Conference, 1997.

21. Aquelet, N. and B. Tutt, A new fluid structure coupling application to parachute modelling. European Journal of Computational Mechanics/Revue Européenne de Mécanique Numérique, 2007. 16(3-4): p. 521-536.

22. Tezduyar, T.E., et al., A new strategy for finite element computations involving moving boundaries and interfaces-the deforming-spatial-domain/space-time procedure: II. Computation of free-surface flows, two-liquid flows, and flows with drifting cylinders. Computer Methods in Applied Mechanics and Engineering, 1992. 94(3): p. 353-371.

23. Tezduyar, T.E., M. Behr, and J. Liou, A new strategy for finite element computations involving moving boundaries and interfaces: the deforming-spatial-domain/space time procedure: I. The concept and the preliminary numerical tests. Computer Methods in Applied Mechanics and Engineering, 1992. 94(3): p. 339-351.

24. Kalro, V., Tezduyar, T., A parallel $3 D$ computational method for fluid-structure interactions in parachute systems. Computer Methods in Applied Mechanics and Engineering, 2000. 190(3-4): p. 321-332.

25. Takizawa, K. and T. Tezduyar, Computational methods for parachute fluid-structure interactions. Archives in Computational Methods in Engineering, 2012. 19: p. 125-169.

26. Takizawa, K., T. Tezduyar, and R. Kolesar, FSI modeling of the Orion spacecraft drogue parachutes. Computational Mechanics, 2015. 55(6): p. 1167-1179.

27. Kim, Y., Peskin, C. S., 3-D parachute simulation by the immersed boundary method. Computer and Fluids, 2009. 38(6): p. 1080-1090.

28. Guruswamy, G.P., Time-Accurate Coupling of Three-Degree-of-Freedom Parachute System with Navier-Stokes Equations. Journal of Spacecraft and Rockets, 2017: p. 1-6.

29. Tutt, B.A., Taylor, A. P., The Use of LS-DYNA to Simulate the Inflation of a Parachute Canopy. 18th AIAA Aerodynamic Decelerator Systems Technology Conference and Seminar. AIAA 2005-1608, 2005. 
30. Tutt, B., et al., Development of parachute simulation techniques in LS-DYNA, in 11th International LS-DYNA Users conference. 2010: Detroit.

31. Coquet Y., et al., Improvements in Fluid Structure Interaction Simulations of Parachutes Using LS-Dyna®. 21st AIAA Aerodynamic Decelerator Systems Technology Conference and Seminar, Dublin, Ireland, paper AIAA 2011-2590, 2011.

32. Ludtke, W., A technique for the calculation of the opening-shock forces for several types of solid cloth parachutes. In 4th Aerodynamic Deceleration Systems Conference, Aerodynamic Decelerator Systems Technology Conferences, AIAA paper 73-477, 1973.

33. Flores, R., Ortega, E., Onate, E., Simple and efficient numerical tools for the analysis of parachutes. Engineering Computations, 2014. 31(5).

34. Ortega, E. and R. Flores, PARACHUTES. A computer program for calculating ram-air parachutes. Theory document. CIMNE publication, 2015.

35. Provot, X., Deformation constraints in a mass-spring model to describe rigid cloth behaviour. Graphics Interface, 1995: p. 147-155.

36. De la Torre, D., E. Ortega, and R. Flores, PARACHUTES. A computer program for calculating ram-air parachutes. User's manual. CIMNE publication, 2015.

37. Li, X., Verification and Validation of the Spring Model Parachute Air Delivery System in Subsonic Flow. State University of New York at Stony Brook research foundation, 2015.

38. Cicolani, L., Kanning, G., A comprehensive estimate of the static aerodynamic forces and moments of the 8- by 8- by 20-Foot cargo container. NASA Technical Memorandum 89433, 1987.

39. Ludtke, W.P., Observations on the inflation time and inflation distance of parachutes. Naval Surface Warfare Center Silver Spring MD. Report No. NSWC-TR-88-292, 1988.

40. Hoerner, S.F., Fluid-dynamic drag: practical information on aerodynamic drag and hydrodynamic resistance. 1965: Midland Park, NJ: Hoerner Fluid Dynamics.

41. Scheubel, F.N., Notes on the Opening Shock of a Parachute. USAF Memorandum Report F-51-10-8507, 1946.

42. French, K.E., Inflation of parachute. AIAA Journal, 1963. 1(11): p. 2615-2617.

43. Barndard, G., The effect of extreme altitude on parachute filling distance. In Aerospace Design Conference, paper AIAA 93-1207, 1993.

44. Mohaghegh, F., Jahannama, M. R., Decisive roll of filling time on classification of parachute types. Journal of Aircraft, 2008. 45(1): p. 267-275.

45. Potvin, J., Universality considerations for graphing parachute opening shock factor versus mass ratio. Journal of Aircraft, 2007. 44(2): p. 528-538.

46. Peek, G., Potvin, J., OSCALC-Opening Shock Calculator Version 1.01, User's Manual. Parks College Parachute Research Group, Saint Louis University, St. Louis, MO., 2006.

47. Berndt, R.D., J., Filling time prediction approach for solid cloth type parachute canopies. In Aerodynamic Deceleration Systems Conference, 1966.

48. Potvin, J., Papke, J., Brighton, E., Farmer, M., Peek, G., A New Inflation Model for LowPorosity Hemispherical Parachutes: Validation and Implementation in PIMS V3. 0. In 18th AIAA Aerodynamic Decelerator Systems Conference and Seminar, Munich, Germany, AIAA Paper 2005-1687, 2005.

49. French, K.E., Initial phase of parachute inflation. Journal of Aircraft, 1969. 6(4): p. 376-378.

50. Heinrich, H.G.S., D. P., Parachute opening shock calculations with experimentally established input functions. Journal of Aircraft, 1978. 15(2): p. 100-105.

51. Ludtke, W.P., Notes on a generic parachute opening force analysis. Naval Surface Weapons Center, Report NSWC TR 86-142, 1986. 
52. Heinrich, H.G.S., D. P. (1972). . . Study of Parachute Forces and Canopy Pressure Distribution Measured in a Subsonic Wind Tunnel Under Infinite Mass Conditions. Minnesota University Minneapolis, Report AFFDL-TR-71-175, 1972.

53. Melzig, H.D.S., P. K., Pressure distribution during parachute opening. Phase I: infinite mass operating case. Air Force Flight Dynamics Laboratory. Report AFFDL-TR-6610, 1966.

54. Potvin, J., Peek, G., Brocato, B., Kutz, R., Manglano, C., Yavitz, B., Deceleration dynamics of unreefed cruciform and flat circular parachutes during and after inflation. In 16th AIAA Aerodynamic Decelerator Systems Technology Conference and Seminar, Boston, MA. Paper AIAA 2001-2028, 2001.

55. Doherr, K., Extended parachute opening shock estimation method. In 17th AIAA Aerodynamic Decelerator Systems Technology Conference and Seminar, Monterey, CA. AIAA paper 2003-2173, 2003.

56. Cockrell, D.J., The aerodynamics of parachutes. AGARDograph № 295. AGARD-AG295, 1987.

57. Heinrich, H.G., Noreen, R. A. , Analysis of parachute opening dynamics with supporting wind-tunnel experiments. Journal of Aircraft, 1970. 7(4): p. 341-347.

58. Kidane, B., Parachute drag area using added mass as related to canopy geometry. In 20th AIAA Aerodynamic Decelerator Systems Technology Conference and Seminar. Paper AIAA 2009-2942, 2009.

59. Heinrich, H.G., A linearised theory of parachute opening dynamics. The Aeronautical Journal, 1972. 76(744): p. 723-731.

60. Klimas, P.C., Fluid mass associated with an axisymmetric parachute canopy. Journal of Aircraft, 1977. 14(6): p. 577-580.

61. Guglieri, G., Parachute-payload system flight dynamics and trajectory simulation. International Journal of Aerospace Engineering, 2012.

62. Lee, C., Experimental investigation of full-scale and model parachute opening. In 8th aerodynamic decelerator and balloon technology conference. AIAA paper 84-0820, 1984.

63. Berndt, R.J., DeWeese, J. H., The opening force of solid cloth, personnel type parachutes. In 3rd Aerodynamic Deceleration Systems Conference. AIAA paper 701167, 1970.

64. Lee, C.K., Modeling of parachute opening-An experimental investigation. Journal of Aircraft, 1989. 26(5): p. 444-451.

65. Lingard, J., A semi-empirical theory to predict the load-time history of an inflating parachute. In 8th Aerodynamic Decelerator and Balloon Technology Conference. AIAA paper 84-0814, 1984. 